\title{
Point thermal bridges of insulated pitched roof structures
}

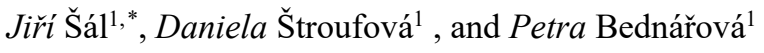 \\ ${ }^{1}$ Institute of Technology and Business in České Budějovice, Department of Civil Engineering, \\ 37001 České Budějovice, Czech Republic
}

\begin{abstract}
The current demands on building insulation are continuously increasing. It is understood that the lower the heat transfer coefficient of a particular part of a construction is, the greater the importance of systemic thermal bridges. This article compares the individual systems of insulation of pitched roofs in terms of the heat transfer coefficient. The focus is on the size of the point thermal bridges in rafter thermal insulation systems and determines their impact on increasing the overall heat transfer coefficient. However, it should be noted that point thermal bridges are individually very small and combined only contribute to $2 \%$ of the overall heat transfer coefficient of parts of a structure.
\end{abstract}

\section{Introduction}

The aim of the research in this paper is to determine the size of point thermal bridges in onrafter thermal insulation systems and to determine their influence on the increase in the total heat transfer coefficient $U$ in relation to the number of anchors and the insulation type. An analysis was carried out on the influence of the position of thermal insulation in an insulated pitched roof structure on the heat transfer coefficient. For the analysis we distinguish between sub-rafter, on-rafter and inter-rafter thermal insulation systems. The inter-rafter system itself is no longer acceptable by today's requirements for heat transfer. The sub-rafter insulation system reduces the inner space of a building, whereby space is lost that might otherwise be used for a different purpose. This is why the inter-rafter and sub-rafter systems are combined with other systems. At present, the following three variants are the most commonly used:

- inter-rafter + sub-rafter,

- inter-rafter + on-rafter,

- on-rafter.

In the first two systems the rafters act as thermal bridges. In contrast, the in-rafter system is often considered to be thermal bridge free. The on-rafter insulation system of pitched roofs has point thermal bridges at the points of anchoring (screws), which increase the heat transfer coefficient.

\footnotetext{
*Corresponding author: sal@mail.vstecb.cz
} 


\section{Comparison of thermal insulations of pitched roofs according to their location in a structure}

A comparison was made of the three thermal insulation systems: inter-rafter + sub-rafter; inter-rafter + on-rafter; and on-rafter, using four thermal insulation thicknesses: $200 \mathrm{~mm} ; 240$ $\mathrm{mm} ; 280 \mathrm{~mm}$; and $320 \mathrm{~mm}$. The values necessary for the comparison were calculated using the Svoboda software - Heat. The thermal insulation was composed of basalt fibres $(\lambda=0.043 \mathrm{~W} /(\mathrm{m} \cdot \mathrm{K})$ and was applied according to the recommended systemic solution of the manufacturers.

As can been seen in Figure 1, the differences in the heat transfer coefficient for the interrafter + sub-rafter system and the inter-rafter + on-rafter system are relatively small. However, these systems differ substantially when compared to the purely on-rafter system. This system has the lowest heat transfer coefficient and is therefore the best from this point of view. The system thermal bridges (rafter influence) were considered in this comparison, however the point thermal bridges were not.

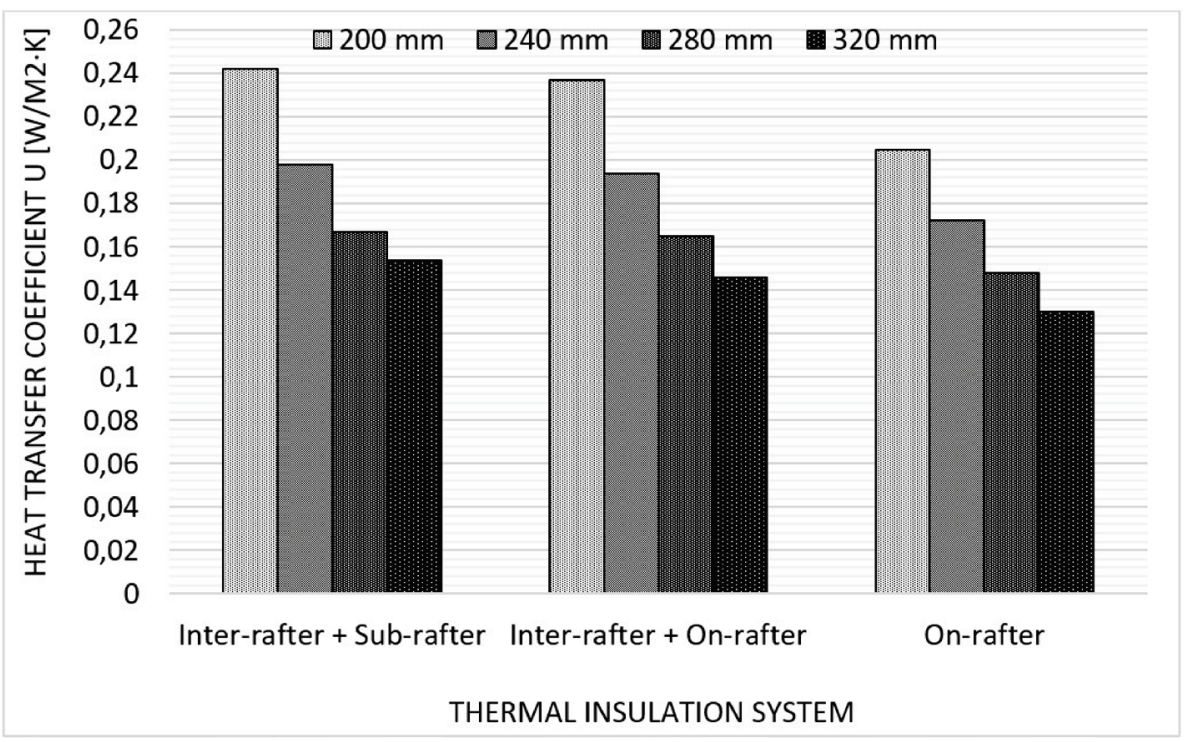

Fig. 1. Comparison of heat transfer coefficients in relation to systemic thermal bridges (wooden rafters) for pitched roof insulation systems [3].

\section{Point thermal bridges}

The calculations and comparison in the previous section show that the on-rafter insulation system is the most advantageous in terms of the heat transfer coefficient for all thermal insulation thicknesses. This system also has the advantage that the location of the thermal insulation layer on the rafters is compact and uninterrupted, as is not the case when the insulation is placed between the rafters. Under this system no systemic thermal bridges occur because of the poor thermal insulation properties of the wooden rafters. Nevertheless, point thermal bridges do occur where there are anchoring elements which are required to fix the thermal-insulation elements, or the supporting structure, into place. To illustrate this, three on-rafter pitched roof thermal insulation systems are described and quantified below. The systemic anchoring elements prescribed by the corresponding manufacturers were used. Different thermal insulation thicknesses were also applied for the comparison. 


\section{Selected thermal insulation compositions}

System No. 1 - Bramac THERM TOP with insulation thicknesses of $140 \mathrm{~mm}, 160 \mathrm{~mm}, 180$ $\mathrm{mm}$ and $200 \mathrm{~mm}$. Figure 1 shows the composition of the system. The insulation material is rigid polyisocyanurate foam (PIR). Bramac THERM TOP systemic screws made of nitride carbon steel with a Duracoat coating were used as the anchoring elements. The length of the required screws was defined by the manufacturer and subject to the thickness of the thermal insulation and boarding. For the purpose of the analysis $300 \mathrm{~mm}, 330 \mathrm{~mm}$ and $360 \mathrm{~mm}$ long screws were used respectively (see Figure 2).

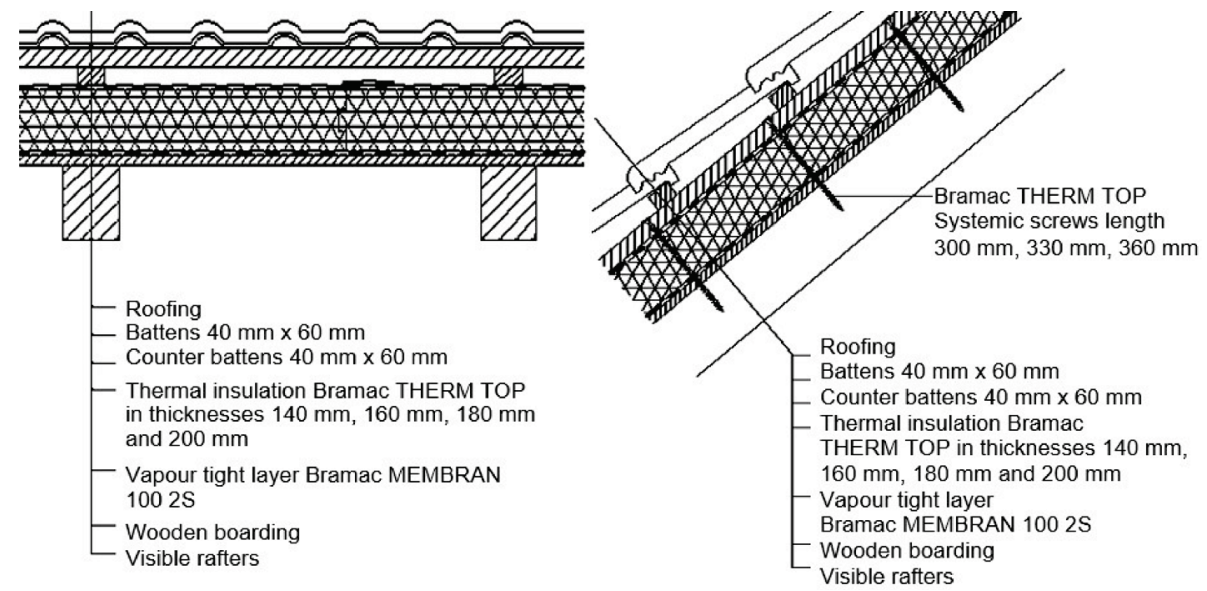

Fig. 2. Cross sections of the Bramac THERM TOP system [3].

System No. 2 - Isover UNI system with basalt fibre thermal insulation as recommended by the manufacturer for on-rafter systems. Thermal insulation thicknesses of $200 \mathrm{~mm}, 240$ $\mathrm{mm}, 280 \mathrm{~mm}$ and $320 \mathrm{~mm}$ were compared. Twin UD systemic double-thread screws and Isover TRAM blocks were the bearing elements for the system. The TRAM blocks are manufactured in two variants - mineral wool blocks and foam polystyrene blocks. Both types were used for the calculations. The length of the screws used, from $400 \mathrm{~mm}$ to $520 \mathrm{~mm}$, depended on the thickness of the blocks. Figure 3 shows cross sections of the system (perpendicular to the rafter and in the plane of the anchoring screws).
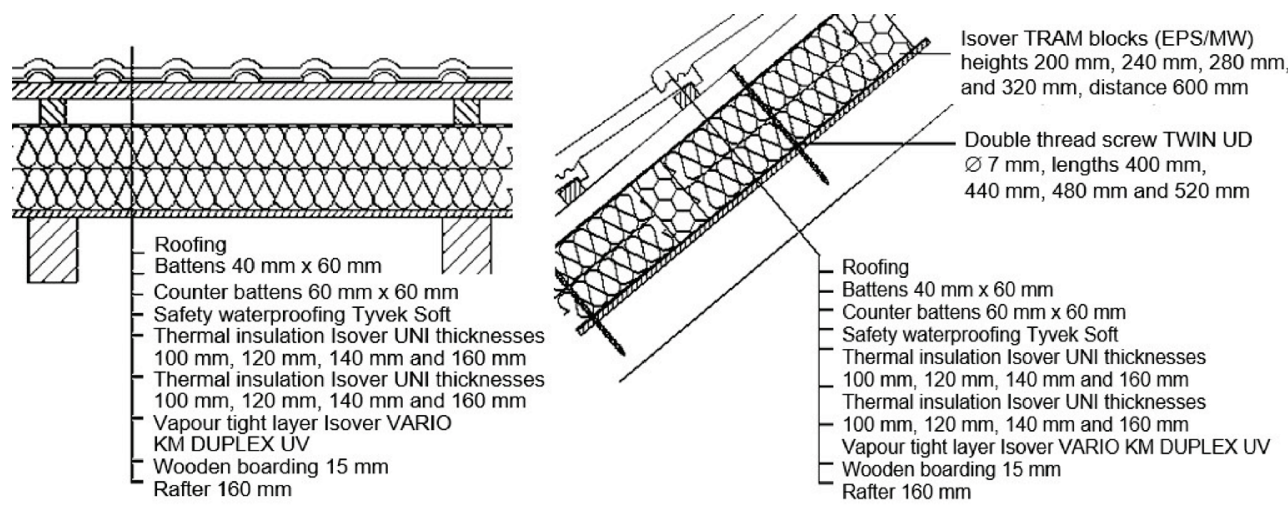

Fig. 3. Cross sections of the Isover UNI system [3].

System No. 3 - ISOTEC using panels made of rigid polyurethane self-extinguishing foam (PUR) with closed cells. The panels are covered with a layer of aluminium foil and have 
integrated roof battens for roof laying. The panes are anchored to the bearing structures through the battens by dowels or steel screws. The length of these prefabricated panels is 3.9 $\mathrm{m}$. They are manufactured in thicknesses of $60 \mathrm{~mm}, 80 \mathrm{~mm}, 100 \mathrm{~mm}$ and $120 \mathrm{~mm}$. For the purpose of the analysis only $120 \mathrm{~mm}$ thick panels were used. The presence of the integrated roof battens on the panels means that the panel thickness determines the batten distance. Each panel is anchored to each rafter. This means for example, with a rafter distance of 1 meter and a panel thickness of approx. $34 \mathrm{~mm}$ the number of anchors is 3 per sq. m. Figure 4 shows cross sections of the ISOTEC system.

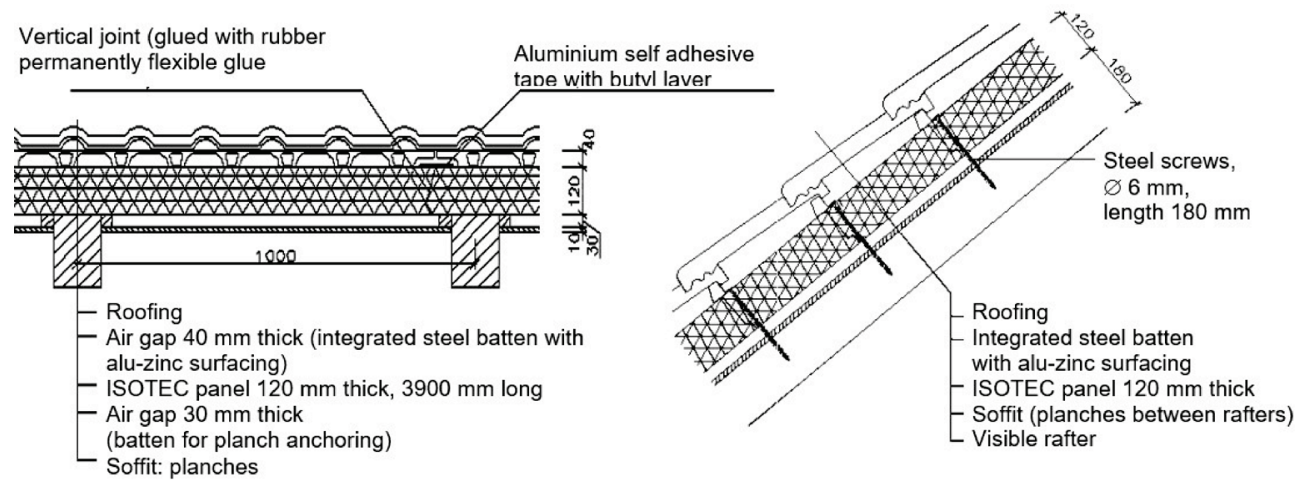

Fig. 4. Cross sections of the ISOTEC system [3].

In all the above systems the distance and the number of anchoring elements depends on the axial distance of the rafters, roofing type (light, heavy), roof inclination, and on the climatic area. Two to three anchoring elements per square meter of roof is considered to be the norm. For the analysis the heat transfer coefficient is calculated for 2 and 3 anchoring elements and for the value in between i.e. 2.5 anchoring elements.

\section{Calculation procedure}

The calculations were performed by means of the QuickField 5.10 software. The software enables us to quantify the point thermal bridges caused by the anchoring elements in an onrafter thermal insulation system. It also enables us to create a two-dimensional thermal field in the $\mathrm{x} ; \mathrm{z}$ coordinate system, as well as solve problems with rotational axes and the cylindrical arrangement in the r; z coordinate system. Small inaccuracies occur in the calculations due to the bar elements in the composition e.g. rafters and battens, with which the anchoring elements directly intersect. These elements have to be adapted in the shape. The anisotropy of these elements can also not be considered in the calculation. The thermal conductivity of these elements was therefore entered as being perpendicular to the fibres, whereby its value is substantially lower than that of the thermal conductivity along the fibres. This also eliminated the imperfect shape input. These small inaccuracies can be disregarded as their values are in hundredths $(\mathrm{m} . \mathrm{W}) / \mathrm{K}$, which is not significant for the evaluation of thermal loss from low energy houses.

\section{Point thermal bridges and their influence on heat transfer coefficient}

The values of the point thermal bridges $\chi[\mathrm{W} / \mathrm{K}]$ for the individual thermal insulation thicknesses and the heat transfer coefficient $\mathrm{U}[\mathrm{W} / \mathrm{m} 2 \cdot \mathrm{K}]$ not including these thermal bridges 
were determined for all the above described systems. The value $\mathrm{U}$, including the point thermal bridges for various numbers of screws per square meter, was subsequently calculated, as was the percentage increase in $U$ in relation to the number of anchors and the type of thermal insulation. The calculated values are summarized in Table 1 and graphically presented in Figure 5.

Table 1. Increase in heat transfer coefficient [3].

\begin{tabular}{|c|c|c|c|c|c|c|c|c|c|}
\hline \multirow{2}{*}{ 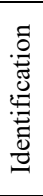 } & \multirow{2}{*}{$\begin{array}{c}\text { Thermal } \\
\text { insulation } \\
\text { thickness } \\
\text { [mm] }\end{array}$} & \multirow{2}{*}{$\begin{array}{c}\text { Heat transfer } \\
\text { coefficient } \\
U \text { not } \\
\text { considering } \\
\text { TBs } \\
{\left[\mathrm{W} / \mathrm{m}^{2} \cdot \mathrm{K}\right]} \\
\end{array}$} & \multirow{2}{*}{$\begin{array}{c}\text { Point thermal } \\
\text { bridge } \\
\text { size } \\
\chi[\mathrm{W} / \mathrm{K}]\end{array}$} & \multicolumn{3}{|c|}{$\begin{array}{l}\text { Heat transfer coefficient } U \\
\text { including the point thermal bridges } \\
\text { for various numbers of screws } \\
{\left[\mathrm{W} /\left(\mathrm{m}^{2} \cdot \mathrm{K}\right)\right]}\end{array}$} & \multicolumn{3}{|c|}{$\begin{array}{c}\text { Percentage increase in heat } \\
\text { transfer coefficient } \\
{[\%]}\end{array}$} \\
\hline & & & & 2 & 2.5 & 3 & 2 & 2.5 & 3 \\
\hline \multicolumn{10}{|c|}{ Bramac THERM TOP } \\
\hline A & 140 & 0.156 & 0.0066 & 0.169 & 0.173 & 0.176 & 108.3 & 110.9 & 112.8 \\
\hline $\mathrm{B}$ & 160 & 0.137 & 0.0062 & 0.150 & 0.153 & 0.156 & 109.5 & 111.7 & 113.9 \\
\hline $\mathrm{C}$ & 180 & 0.123 & 0.0059 & 0.135 & 0.137 & 0.140 & 109.8 & 111.4 & 113.8 \\
\hline $\mathrm{D}$ & 200 & 0.111 & 0.0056 & 0.122 & 0.125 & 0.128 & 109.9 & 112.6 & 115.3 \\
\hline \multicolumn{10}{|c|}{ Isover UNI + foam polystyrene blocks } \\
\hline $\mathrm{E}$ & 200 & 0.176 & 0.0057 & 0.187 & 0.190 & 0.193 & 106.3 & 108.0 & 109.7 \\
\hline $\mathrm{F}$ & 240 & 0.148 & 0.0052 & 0.158 & 0.161 & 0.163 & 106.8 & 108.8 & 110.1 \\
\hline G & 280 & 0.127 & 0.0047 & 0.137 & 0.139 & 0.142 & 107.9 & 109.4 & 111.8 \\
\hline $\mathrm{H}$ & 320 & 0.112 & 0.0044 & 0.121 & 0.123 & 0.125 & 108.0 & 109.8 & 111.6 \\
\hline \multicolumn{10}{|c|}{ Isover UNI + mineral wool blocks } \\
\hline I & 200 & 0.185 & 0.0057 & 0.196 & 0.199 & 0.202 & 105.9 & 107.6 & 109.2 \\
\hline $\mathrm{J}$ & 240 & 0.155 & 0.0052 & 0.166 & 0.168 & 0.171 & 107.1 & 108.4 & 110.3 \\
\hline $\mathrm{K}$ & 280 & 0.134 & 0.0048 & 0.143 & 0.146 & 0.148 & 106.7 & 109.0 & 110.4 \\
\hline $\mathrm{L}$ & 320 & 0.118 & 0.0044 & 0.127 & 0.129 & 0.131 & 107.6 & 109.3 & 111.0 \\
\hline \multicolumn{10}{|c|}{ ISOTEC } \\
\hline M & 120 & 0.194 & 0.0037 & 0.201 & 0.203 & 0.205 & 103.6 & 104.6 & 105.7 \\
\hline
\end{tabular}

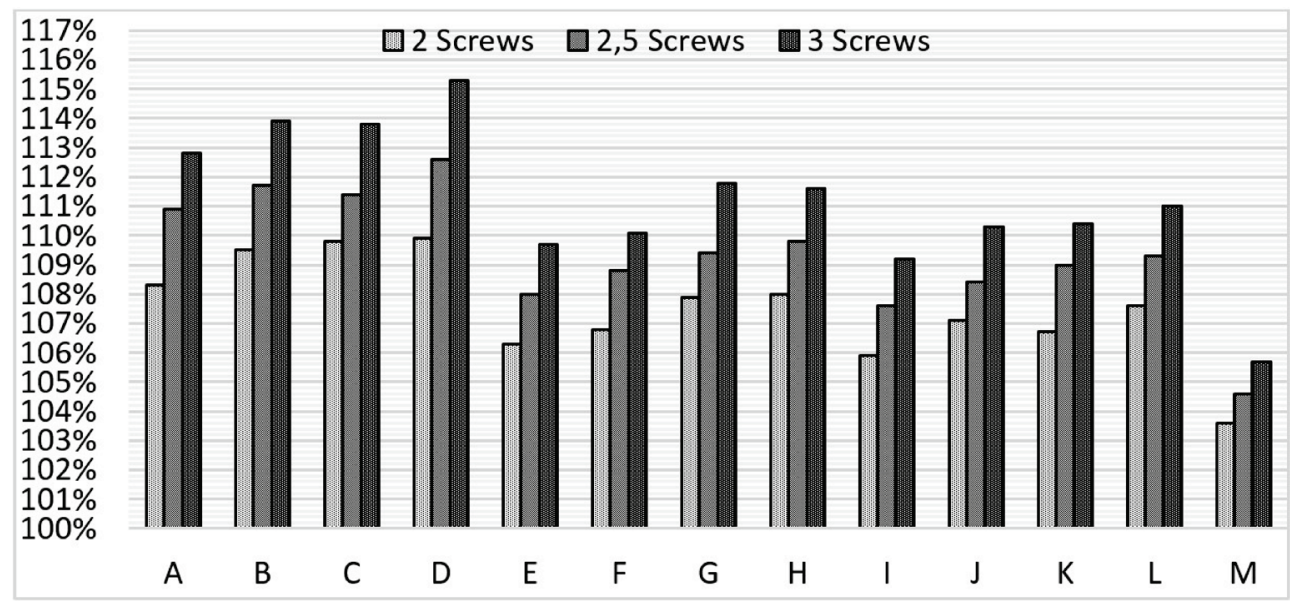

Fig. 5. Percentage increase in heat transfer coefficient $U$ in relation to the type of thermal insulation and the number of anchors [3].

As the results show, there are considerable differences in the change in the heat transfer coefficient between the individual on-rafter systems caused by point thermal bridges even 
where the thickness of the thermal insulation is the same. Even though the values of the point thermal bridges are relatively low, they play an important role with regards to the low values of the heat transfer coefficient and their number per square meter.

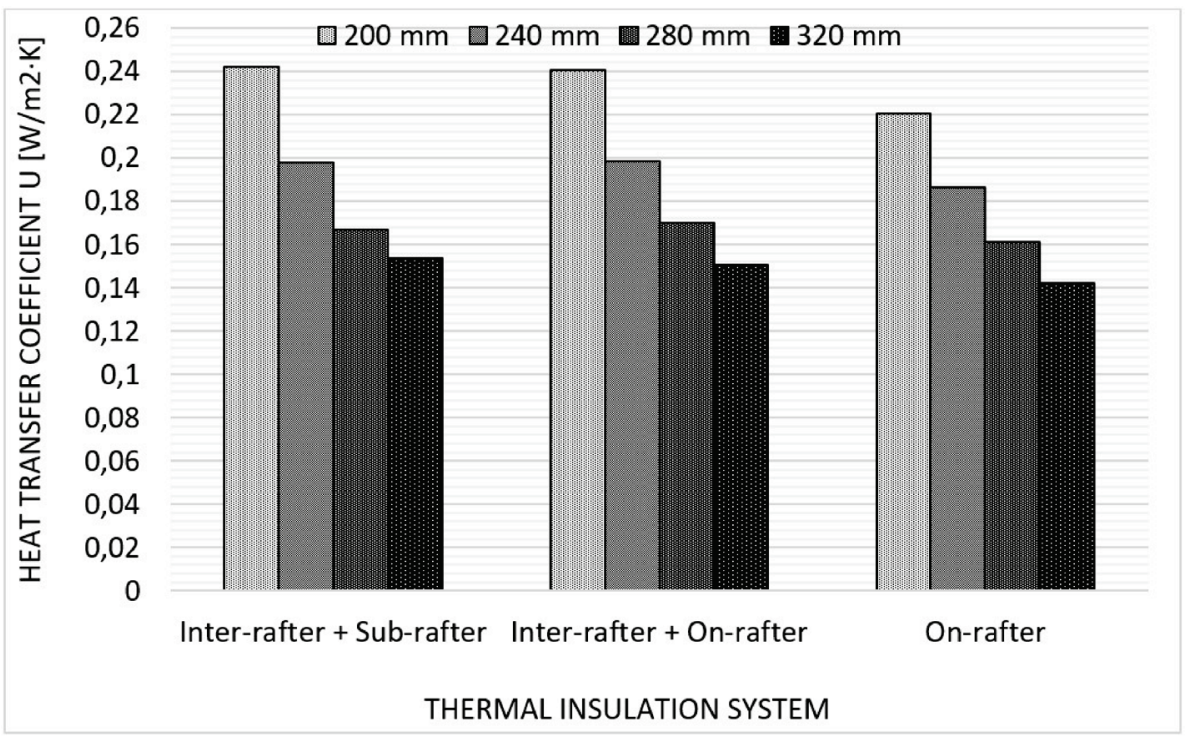

Fig. 6. Comparison of heat transfer coefficients in relation to systemic and point thermal bridges for pitched roof insulation systems [3].

\section{Conclusion}

The issue of systemic and point thermal bridges is of great importance in the field of thermal technology. The ever increasing requirements with regards to the thermal properties of constructions means that there is increasing pressure to resolve the issue. Even though thermal bridges contribute substantially to total thermal losses, they do not always receive the attention they should.

Having the lowest possible energy requirements should be the aim of each construction project, irrespective of whether it concerns a reconstruction or a new build. It is therefore necessary to limit energy requirements as much as possible, or at least to accurately determine the places where thermal loss occurs in a construction, or a part thereof, and to try and find a constructional solution that will resolve the problem. The lower the heat transfer coefficient of a particular part of a construction, the greater the importance of systemic thermal bridges.

\section{References}

1. R. Šubrt, P. Charvátová. Passive Houses 2013: Collection of Contribution, 111-116, (STU Bratislava, Košice, 2013)

2. R. Šubrt. Thermal bridges: for low energy and passive houses: 85 Well-proven and Calculated Construction Details (Grada, Prague, 2011)

3. P. Bednářová, D. Štroufová. Point Thermal Bridges - Research Assignment (ITB, České Budějovice, 2013)

4. Scudder Roofing, Available on http://www.scudderroofing.com/roofing-roofshistory.htm 